\title{
World Income Inequality Between and Within Regions: 1820-2008
}

\author{
Keisuke Kokubun ${ }^{1}$ \\ ${ }^{1}$ International Economy and Work Research Institute, Osaka, Japan \\ Correspondence: Keisuke Kokubun, International Economy and Work Research Institute, 3-14 \\ Kitahama-Higashi, Chuo-ku, Osaka, 540-0031, Japan. Tel: 81-6-6943-9490. E-mail: kokubun@iewri.or.jp \\ Received: May 18, 2017 \\ Accepted: June 17, 2017 \\ Online Published: July 5, 2017 \\ doi:10.5539/ijef.v9n8p1 \\ URL: https://doi.org/10.5539/ijef.v9n8p1
}

\begin{abstract}
This study investigates the world income inequality between 1820 and 2008 decomposing international inequality into between- and within-region factors. Our estimates show increase of inequality between 1820 and the 1960s. Within-region inequality increased a lot in the very long run, mainly led by within-West inequality in nineteenth century and by within-East Asia inequality in the latter half of twentieth century. However, between-region inequality increased more significantly and was the main cause behind the very strong increase in global inequality in these two centuries. This process appears to have come to an end during the second half of twentieth century, a high level of stagnation of world inequality inthe 1970s and the 1980s followed by a decline inthe 1990s and more strongly in the 2000s, mainly due to the rapid growth in countries such as China, India, Indonesia, etc. This decline in world inequality was accompanied by decrease of between- and within-region inequality, although the speed of the former is faster than the latter.
\end{abstract}

Keywords: inequality, economic development, world, region, Gini coefficient, Theil index, decomposition

\section{Introduction}

Today, many companies are coming to face significant internal income gap. The reason of rising inequality is different by countries: e.g. in Japan that is normally attributed to the fact that formal employees are substituted with contract workers due to companies' massive relocation to overseas countries and accordingly the payment level of contract workers are depressed to the ones of China and neighboring countries. On the other hand, companies which have advanced to overseas countries are considered to have pushed up thelevel of local economy and at the same time have enlarged gaps between the ones who gain or do not gain the benefits of economic development successfully. However, it is still unclear and difficult to be imaged how these stacked phenomena have contributed to increase or decrease of total world inequality as there are many regions and countries in the world and the conditions where they are placed are different one by one. For example, one may expect that inequality between the West and East Asia has decreased due to the strong economic development of the latter in recent decades. Or, at the same time inequality within East Asia may have increased as it is well known that there are differences on the timings of 'take off' and length and strength of flying-geese development (Akamatsu, 1962) by countries. Furthermore, supposing the stories above are true, then what can we consider about the change of total inequality in the world? Of courseit should be the aggregated figure of several fragments which appear between or within regions but difficult to be imaged without any numerical data.

With such interest, this paper's main contribution is a detailed description of the evolution of world income inequality over the last two centuries decomposing inequality to between- and within-region fragments. In Section 2, the paper first reviews previous literature regarding this theme. In Section 3, the paper looks at the data and the methodology used to reconstitute the world distribution of income while taking regional or inter-regional income disparities into account. Section 4 presents the findings on the overall evolution of world income distribution since 1820 and provides a partial explanation of its changes by decomposing into the contribution of two components: inter-regional inequality and regional inequality. The main findings are summarized in the concluding section.

\section{Literature Review}

The aim of this paper is to present new estimates of global inequality between 1820 and the present, based on the available historical data, and to analyze the main results that emerge from these estimates. The enormous increase of inequality on a global scale is one of the most worrying features of the development of the world 
economy in the past 200 years. For this reason, the subject has become one of the most discussed topics in the social science and many attempts have been made to estimate changes in world inequality (Anand \& Segal, 2008). Inequality has been defined as inter-country inequality of per capita incomes or as a combination of between- and within-country inequality. A paper that has attempted to do the latter, i.e. Bourguignon and Morrisson (2002), is for the period before 1950 largely based on the assumption that income inequality within countries is unchanging, as a result of which changes in income inequality within countries are clearly underestimated. On the other hand, Zanden, Baten, Foldvari, and Leeuwen (2014) overcome this shortage incorporating estimated figures of within-country inequality into the total inequality, but for that reason the number of countries was reduced in exchange for consistent way of calculation of income inequality.

Although it is obvious that these research greatly contributed to our understanding of the extent of world income inequality, at the same time the researcher still finds difficulties in following long-term trend of inter country inequality as long as we persist in the contrast of between- and within-country inequality. Besides, the researcher considers that we have not yet made full uses of inter-country data in the research. Based on such understanding, we focus only on inter-country inequality in this paper. A possible justification for this choice is that international inequality tends to change more quickly and more dramatically than national differences andtherefore, the dynamics of the world distribution of income would derive mainly from the component of world inequality that arises from the evolution of differences between countries rather than within countries (Firebaugh, 2003). This paper focuses on a longer period and takes a more general perspective on world inequality than previous work. Because the analysis begins in 1820, it takes into account the major effects that the Industrial Revolution had on the world distribution of income. Because the analysis looks explicitly at the distribution of income within and between regions, it evaluates world inequality comparatively.

Our aim is to present new estimates of inter-country global inequality, because we think we lack the historical and consistent estimates to really understand these patterns of changing global inequality in detail. We have created new estimates to understand the evolution of global inequality in the nineteenth and twentieth centuries computing its between- and within-region components. Our main contribution is that we greatly enlarge the number of observations on which the estimates are based: Kokubun, Ikemoto and Hamashima (2006) who used the most similar methodology of this paper had 75 countries, whereas we have 129 and 222 countries depending on the length of year forcalculation. These countries represent 77.4 and 100 percent of the world's population (according to the Maddison estimates). We think this dataset is more representative of global trends than previous research of inter-country inequalities.

\section{Methods}

\subsection{Measures}

As the main purpose of this paper is to present new estimates of global income inequality attributing it to between- and within-region factors, the calculation method has to be (1) general and (2) decomposable. In this sense, the Gini coefficient fulfills the condition 1 because it has been the most popular method for measuring income inequality among a number of alternative methods. However, it has several weaknesses including incapability of differentiating different kinds of inequalities.Therefore, for the purpose of making up this shortcoming, we complimentarily use Gini coefficient and Theil index whose advantage over the former is that it is fully decomposable between components fulfilling the condition 2 .

\subsection{Data}

Data on PPP based GDP (1990 International Geary Khamis dollars) and population are from The Maddison-Project (2013), the first to construct a consistent historical series starting as early as 1820 for some countries and ending in 2008. We do not deal with the discussions about the reliability of the Maddison dataset since this is sufficiently available in the existing literature. For five, two and fifteen countries composing former Yugoslavia, former Czechoslovakia and former USSR, respectively, we used the former units to maintain consistency of the largest number of countries for a long period. Besides, missing values were estimated only by interpolation but not by extrapolation. Accordingly, consistent two data sets were prepared: The one is of 129 countries between 1820 and 2008 and the other is of 222 countries between 1950 and 2008. The former covers 59.2, 91.6 and 77.4 percent of the number of countries, GDP and population in the world (figures are shares of the 129 countries in the 222 countries in 2008). According to these figures, we can easily estimate that the average income of the countries covered by this experiment is slightly higher than that of the world as a whole, but the average income of the uncovered rest is clearly lower than of the covered countries. We therefore more or less consistently underestimate inequality, but the bias does not change so much overtime. To permit a inter and intra regional analyses of the evolution of the distribution of world income, the 222 countries were aggregated 
into six blocks, defined geographically or historically: the West, Eastern Europe, Latin America, East Asia, West Asia and Africa (See Appendix A).

Our estimates consist of two components, the within- and the between-region inequality. Figure 1 decomposes world inequality calculated by 129 countries into that due to income disparities within and between regions, using Theil index. The within-region component of inequality is obtained by difference and corresponds to average region inequality weighted by total income. The between-region component refers to the inequality that would be observed if incomes were identical within each region. Within-region inequality is divided to above-mentioned six blocks. Among them, Within-East Asia fragment, the largest component of total within inequality today, is also shown in Figure 1 (For more detail, see Appendix B).

\section{Results}

\subsection{The Long Term Development of Global Inequality}

Compared to Kokubun, et al. (2006), our estimates are somewhat higher than theirs by on average 0.017 points on the Gini coefficient and 0.030 points on the Theil index. Their estimates of global inequality increase from Gini of 0.181 in 1820 to 0.393 in 1900, 0.446 in 1930, and 0.565 in 1970, whereas the Gini estimated here is 0.151 in 1820, and rises to 0.418 in 1900, 0.470 in 1930, and 0.560 in 1970. By Theil index, theirs are 0.071 in 1820 to 0.285 in 1900, 0.349 in 1930 and 0.522 in 1970, whereas ours are 0.053 in 1820 to 0.314 in 1900, 0.385 in 1930 and 0.549 in 1970. The possible reasons of such differences are: 1) the number of countries increased (nevertheless the share of China's GDP in the world GDP in 1820 has increased from 31.8 to 35.5 percent); 2) data are amended (e.g. China's per capita GDP in 1820 has changed from 523 to 600 dollars). From 1820 to 1970, our estimates show increase of world inequality 271 percent by Gini and 940 percent by Theil (Our estimates in this paragraph are calculated by the data of 129 countries).

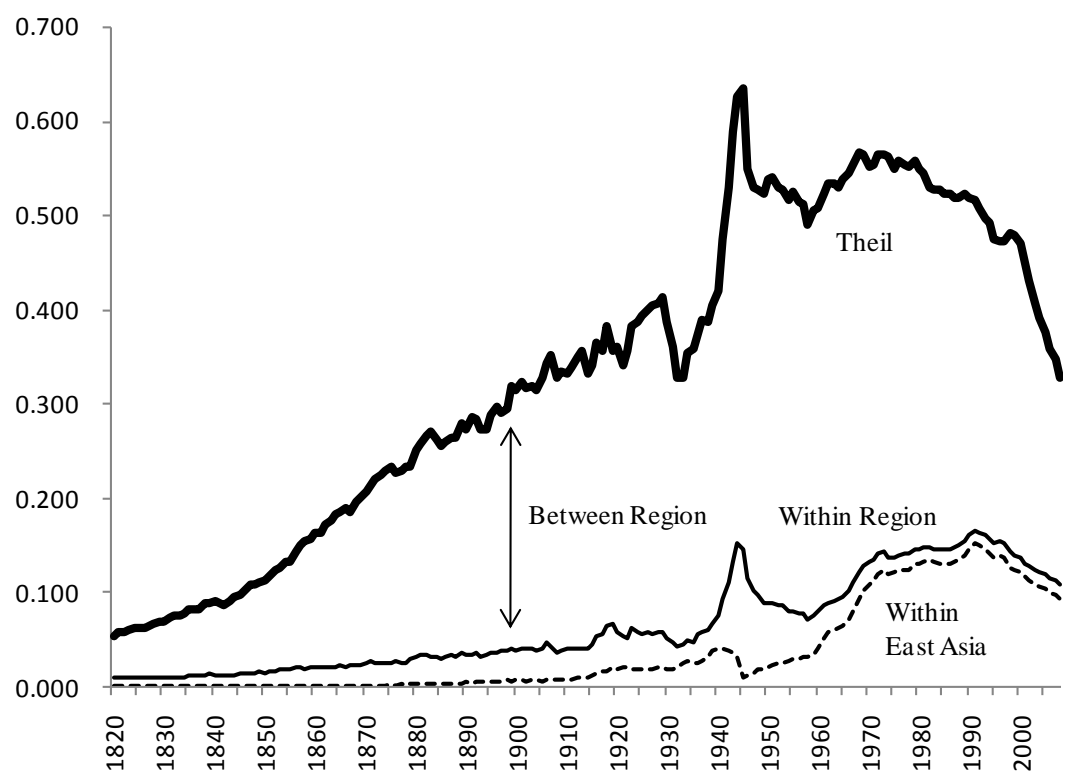

Figure 1.World inequality between and within region 1820-2008 (129 countries)

As outlined above, global inequality increased between 1820 and the 1960s. However, most of the increase occurred before 1945, while global inequality remained stable afterwards until it started to decline in the late 1980s or in the 1990s (This pattern, however, is largely driven by between-region inequality, which increased strongly between 1820 and 1945, maintained stable between 1945 and the 1960s and declined afterwards). This is also consistent with the finding of Kokubun et al. (2006) and Bourguignon \& Morrisson (2002) (with different methodology) who find a similar increase between 1820 and 1945, maintained stable in the 1970s and the 1980s and followed by decrease afterwards. So, in so far as overall trend of world inequality, there is no significant difference between the estimate of Kokubun et al. (2006) and ours, except for a sharp decrease of inequality in the 2000s in our estimate, which is although supportive to other recent estimates (Milanovic, 2011; Pinkovskiy \& Sala-i-Martin, 2009). 
For reference, our estimate by 129 countries change from 0.555 in 1950 to 0.540 in $1960,0.560$ in $1970,0.557$ in 1980, 0.542 in 1990, 0.506 in 2000 and 0.429 in 2008 by Gini and 0.536 in 1950, 0.506 in 1960, 0.549 in 1970, 0.548 in 1980, 0.518 in 1990, 0.468 in 2000 and 0.327 in 2008 by Theil. On the other hand, our estimates by 222 countries change from 0.548 in 1950 to 0.540 in 1960, 0.564 in 1970, 0.568 in 1980, 0.560 in 1990, 0.540 in 2000 and 0.484 in 2008 by Gini and 0.528 in 1950, 0.509 in 1960, 0.556 in 1970, 0.565 in 1980, 0.559 in 1990, 0.533 in 2000 and 0.413 in 2008 by Theil (Figure 2. For more detail, see Appendix C). The estimates by 222 countries are somewhat higher than those by 129 countries by on average 0.014 points on the Gini coefficient and 0.027 points on the Theil index due to inclusion of a larger number of lower income countries in the former.

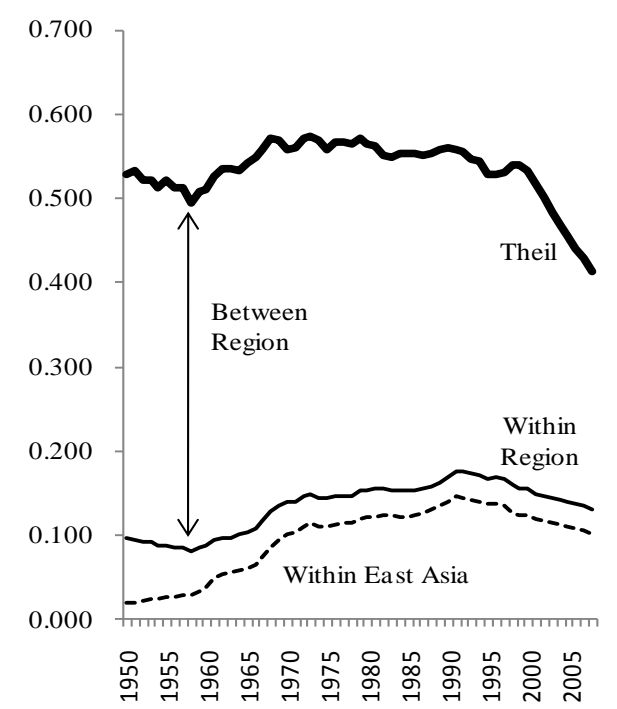

Figure 2.World inequality between and within region 1950-2008 (222 countries)

\subsection{More Precise View}

The largest contribution of this paper is review of more precise trend of world inequality by decomposition of it into between- and within- region fragments. Indeed, the initial decline already took place between 1929 and 1932 when the Great Depression occurred in large parts of the world (most notably in the West). As the effect of depression was greater in high income Western countries than in other place, decrease of global inequality was mostly driven by decrease of between-region inequality. However, this decline was soon canceled out by increase of between- and within- region inequality between 1932 and 1945, which was caused partly by recovery of the Western countries from depression between 1932 and 1939 and greatly by the beginning of World War II between 1939 and 1945. During the war, some countries such as the United States and Canada were not the field of battle and gained an enormous profit due to war economy by lend-lease to the Allies. These two countries' GDP per capita increased 78.5 and 49.6 percent respectively between 1939 and 1945 (and also, that of the United Kingdom increased 12.7 percent in this period), whereas that of most other nations decreased in the same period. For example, per capita GDP of France, Germany, Italy, Japan and China decreased 46.3, 16.5, 45.4, 52.2 and 10.7 percent respectively between 1939 and 1945 . Therefore strong increase of world inequality in this period between 1939 and 1945 was due to simultaneous increase of both between region (mainly between Western particular countries and the rest of the world) and within-region (mostly within-West) inequality. However, this increase of world inequality was soon canceled out by its decrease between 1945 and 1949 due to recession after the war in particular countries: per capita GDP of the United States, Canada, the United Kingdom (the countries not the field of battle in World War II) and Germany (the country divided and ruled in this period) decreased 23.6, 1.0, 1.4 and 27.3 percent respectively. Meanwhile, most other countries were restored in this period: per capita GDP of France, Italy and Japan (the most damaged countries during the war) increased 92.2, 69.8 and 33.7 percent respectively. Therefore, the decrease of world inequality between 1945 and 1949 was driven by the decrease of both between-region (mainly between the West and Japan) and within-region (mostly within-West) inequality. After small increase of inequality led by between-region inequality between 1949 and 1950 mainly due to economic recovery of Germany (its per capita GDP increased 18.2 percent between 1949 and 1950), the process of equalization continued in the 1950s led by decreases of between region (mainly between the West and Japan) and within-region (mostly within West) inequalities. The latter is due to economic convergence in the 
western countries while the former is primarily attributed to continued progress of Japan supported by Korean War which began in 1950 and brought a special procurement boom to it. Although inequality within East Asia had continuously increased since the end of war, it had not been as significant as canceling out these effects of equalization yet.

Following the chaotic times after World War II, world inequality started to increase again led by both betweenand within-region inequality in the 1960s because of the Western countries' continuous development and Japan's catching up to these countries leaving most other countries low-income state. This period corresponds to the one so called 'North-South divide', i.e. the problems created by the differences between developed and developing countries, became the most important theme globally. However, global inequality remained virtually stable during the 1970s and the 1980s because slight decrease of between-region inequality and slight increase of within-region inequality (mostly within-East Asia inequality) canceled out each other, both of which were caused mainly by some of East Asian countries' catching up to the West and Japan enlarging divergence of economic stage among the countries in this region. After the 1990s, global inequality finally started to decrease led by decrease of both between- and within-region inequality. We can observe the effect of Asian currency and economic crisis in 1997 which enhanced the between- and within-region inequality temporarily, although its magnitude was not fully significant to interrupt the long-term trend of equalization till 2008 (Figure 2).

However, it is still far from the condition that the world has become fully equal on the economic level. Rather, world inequality is still extremely large, as significant as the one in the 1900s. The reason is, of course, that there is a large number of countries stagnated at low economic growth. They are mostly Asian and African countries, especially observed at the latter. Indeed, the inter-region inequality between East Asia and Africa is becoming large. In 1950, per capita GDP 889 dollars of Africa was higher than the one of 667 dollars of East Asia. However, in 2008, per capita GDP of Africa stays 1,780 dollars, which is more than three times lower than the one of East Asia 5,512 dollars and more than four times lower than the average of the world 7,614 dollars. Furthermore, within region inequality in Africa is increasing straight forwardly, with no indication of turning-point appearance even today. That means higher income countries develop faster, while low income countries stagnate with low economic stage in this region. Especially, the gap of two highest income countries in this region, i.e. Equatorial Guinea and Mauritius, and other countries are becoming large due to sharp economic development of the former and stagnation of the latter. Within-Africa inequality account for 7.3 percent of total within-region inequality and 2.3 percent of world inequality in 2008, which are the figures cannot be overlooked.

On the other hand, inequality within West Asia is more fluctuating mainly due to booms and busts of oil producing countries. For example, three highest income countries at that time in this region, Qatar, the United Arab Emirates and Kuwait, experienced huge decrease of per capita GDP by 74.5, 49.6 and 53.9 percent respectively between 1970 and 1980 because a period of rapid growth in the 1970s hit a major inflection point to the downside brought aboutby lower oil prices (Haouas \& Heshmati, 2014). From the late 1980s inequality increased again due to increase of per capita GDP pushed up by oil price recovery and successful diversification of industrial structures of these countries plus the strong economic development through successful industrialization of Israel, leaving other companies low income state.

Latin America showed convergence during 1970s and 1980s due to recession of the two highest income countries, Venezuela and Argentina, and catching-up development of other countries. Per capita GDP of Venezuela and Argentina decreased 24.3 and 17.7 percent between 1977 and 1985, due to the collapse of oil prices for the former and the debt crises for the latter. However, Chile's strong economic development since the late 1980s overturned this trend and inequality started to increase again, followed by a high level of stagnation since the 1990s due to economic recovery of comparatively high income countries in this region, i.e. Venezuela, Argentina and Uruguay. Although other comparatively low income countries have develop steadily too, their speeds have not reached the higher income ones and accordingly have had no significant impact to lower inequality in this region by today. Eastern Europe has showed similar convergence of per capita GDP since 1950. However, since the late 1970s, the process of equalization has stagnated due to the difference of development speed among countries, although they have continued steady development till today. The figures of within-region inequality of Latin America and East Europe account for 1.4 and 0.3 percent of total inequality in the world today, respectively (Figure $3 \& 4$ ).

As outlined above, global inequality increased strongly between 1820 and the 1960s, while remained virtually stable afterwards until it started to decrease in the 1990s. This pattern, however, is largely driven by between-region inequality. On the other hand, until the early twentieth century, within-region inequality was mostly driven by within-Western inequality. Increase of within-Western inequality started early ninetieth century due to the growing divergence of economic levels in this area after the Industrial Revolution which took place 
first in UK. However, its share decreased gradually from the late ninetieth century as within-East Asia inequality was becoming larger driven by the economic development of Japan after the Meiji Restoration and subsequent industrial development policies since the 1860s. The magnitude of within-East Asian inequality started to increase sharply in the 1910s because Japan experienced a great advancement in industrial power and enjoyed the economic growth due to World War I between 1914 and 1918. In the 1930s this inequality increased more sharply as Japan strongly recovered from the depression by increase of exports (half of them were to colonized and half colonized countries) which induced stimulation of private investment by ripple effect (Hatase, 2002; Yamazawa \& Yamamoto, 1979). During the Pacific War between 1941 and 1945, as the rate of economic growth in Japan fell into the negative due to the worsened war situation, within-East Asia inequality decreased gradually till 1944 and sharply in 1945 by losing the war and consequent destruction of the economy in Japan where GDP per capita decreased by 2.5 percent per year between 1941 and 1944 and by 49.4 percent between 1944 and 1945 . After 1945, within-East Asia inequality increased again mainly due to Japan's postwar restoration. Especially, in the 1960s, Japan's high economic growth brought the sharp increase of within-East Asia inequality. However, in the 1970s, as other Asian countries such as the four dragons (i.e., South Korea, Hong Kong, Taiwan and Singapore) followed by ASEAN countries (Thailand, Malaysia, Indonesia and Philippines) took off and started flying geese pattern industrial development (Akamatsu, 1962), the widening speed of inequality within-East Asia became down, although still continued to increase till the 1980s. After the 1990s, as China and India started economic development strongly catching up with more advanced countries, within-East Asia inequality started to decrease. Meanwhile, within-West inequality dramatically decreased after the World War II, by strong economic convergence between countries in this region (World Bank, 2009) which continued until the 1970s.

To sum, global inequality has been growing during the last two centuries, mainly because the technological progress advanced by the Industrial Revolution pushed up between-region inequality, but started to decline in the last two decades because globalization in trade and technological transfers through foreign direct investments in emerging countries pushed down between- and within-region inequality. Transfers of technology, know-how and business models from advanced to emerging economies have took place at an increasing pace and allowed for a rapid assimilation of poor regions into the world markets. This implies that the speed at which poor countries will be able to catch up with more advanced economies is increasing over time. Despite this, we still have a wide gap in per-capita incomes across countries, which is not likely to disappear very soon. The speed of technology transfers is not a sufficient condition for convergence. Lacks of human capital and bad institutions are probably the most important factors behind the poorer countries' difficulties in catching up with the western hemisphere (Reichlin, 2013).

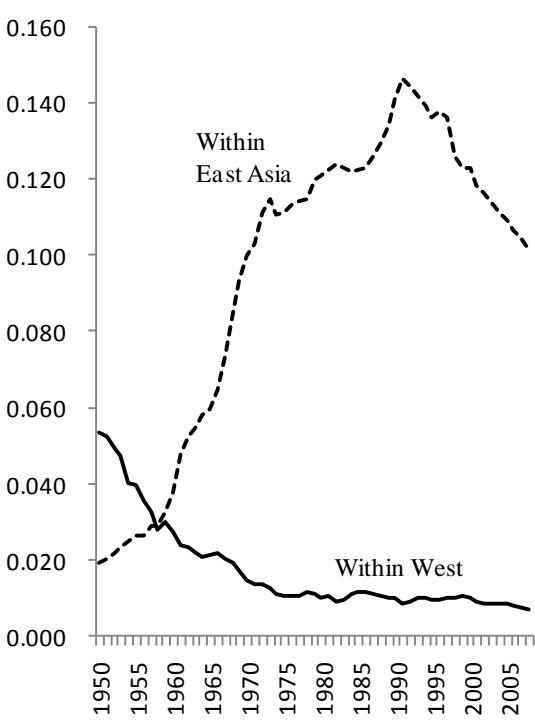

Figure 3. Inequality within West and East Asia 1950-2008

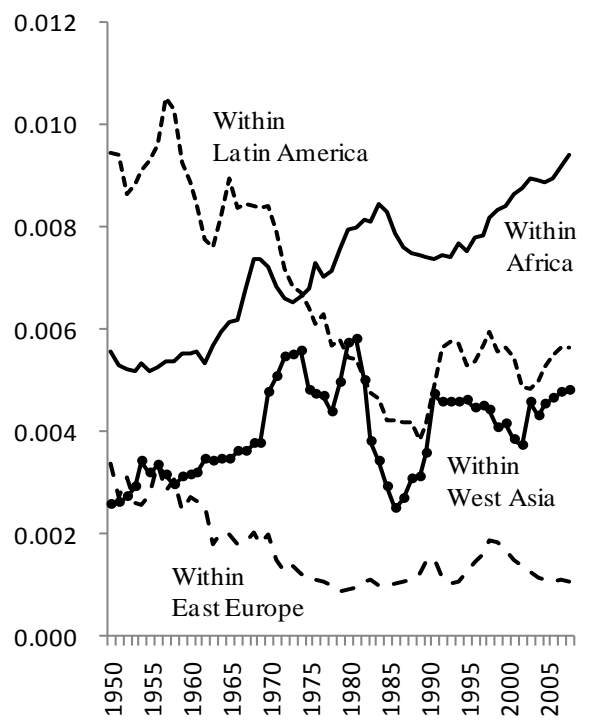

Figure 4. Inequality within East Europe, Latin America, West Asia and Africa 1950-2008

\section{Conclusion}

We reconstructed new estimates of the inequality of income distribution for a larger set of countries than 
previous work for benchmark year starting in 1820 and ending in 2008 using the data set, PPP based GDP and population of Maddison. We presented estimates in both Gini and Theil coefficients, together with decomposed fragments, between-region and within-region inequality. The long-term evolution of global inequality that emerges from this is not very dissimilar from the results presented by Kokubun, et al. (2006). Our estimates show a more or less similar increase during the 1820-1960s. Within-region inequality increased a lot in the very long run, mainly led by within-West inequality in nineteenth century and by within-East Asia inequality in the latter half of twentieth century. However, between-region inequality increased more significantly and was the main cause behind the very strong increase of global inequality in these two centuries. This process appears to have come to an end during the second half of twentieth century, a high level of stagnation of world inequality during the 1970s and the 1980s followed by a decline in the 1990s and more strongly in the 2000s, mainly due to the rapid growth in countries such as China, India, Indonesia, etc. Accordingly, this decline of world inequality was accompanied by decrease of between- and within-region inequality, although the speed of the former is faster than the latter.

To summarize by more concrete figures, this analysis shows that the world income inequality worsened dramatically over the past two centuries: The Gini coefficient increased 271 percent and the Theil index 940 percent between 1820 and 1970 by the data of 129 countries. This evolution was due mainly to a dramatic increase in inequality across countries or regions of the world. The 'between' component of the Theil index went from 0.044 in 1820 to 0.417 in 1970 . Changes in inequality within regions were important in some periods, most notably the increase in inequality within East Asia during the latter half of the 20th century from 0.019 in 1950 to 0.141 in 1990 by the data of 222 countries. In the long run, however, the increase in inequality across regions was the leading factor in the evolution of the world distribution of income as it dominated more than 70 percent of the total inequality throughout most of the period. After the sharp and steady decrease of inequality, 10.4 percent by Gini and 22.5 percent by Theil from 2000 to 2008, which we have never experienced before in two centuries, we may say that the burst of world income inequality has been over. Indeed, there is little difference between the world distribution today (Gini 0.429; Theil 0.327) and in 1905 (Gini 0.428; Theil 0.327) by the data of 129 countries. This does not mean that the distribution has become stable or that a convergence witnessed among Western countries until the 1970s is beginning to take place on a world scale. Rather, we should focus on the change of the nature of inequality: Within-region inequality accounts for only 16.8 percent in 1960 , however it accounts for 31.4 percent in 2008. Here, within-East Asia inequality accounts for 78.4 percent of total within-region inequality. Comparatively, inequality in East Asia is becoming more and more important to consider the world problem of income inequality. Besides, we cannot overlook the fact that inter-regional inequality in the third world, i.e. between East Asia and Africa, and intra-regional inequality in Africa are becoming large to the extent meaningfully affective to the world total inequality. Besides, we have to take note the fact intentionally skipped in this paper that inequality within most countries is increasing, notably in highly populated countries such as China and the United States (Bosmans, Decancq, \& Decoster, 2014). It is considered that facilitated migration of companies and people over national boarder have contributed to enlarged domestic income gaps in many countries and at the same time to diminished income gaps between countries. In that sense, inequality between countries is interrelated with that of within countries.

\section{Study Limitations and Suggestions for Future Research}

There are three significant limitations on this research. The first one is about the range of inequality. We didn't take into account within-country inequality although it is well known that such inequality is becoming large in recent decades. The second limitation is about the nature of data. We used PPP based GDP only and didn't use others (e.g. nominal GDP) for calculation of inequality. If we use the latter, the result will be different. The last limitation is about the definition of inequality. We calculated 'comparative' inequality only although it is known that 'absolute' inequality has been increasing till today (Goda \& García, 2016). Future research will cover these limitations.

\section{References}

Akamatsu, K. (1962). A historical pattern of economic growth in developing countries. The Developing Economies, 1(s1), 3-25. http://dx.doi.org/10.1111/j.1746-1049.1962.tb00811.x

Anand, S., \& Segal, P. (2008). What do we know about global income inequality? Journal of Economic Literature, 46(1), 57-94. http://dx.doi.org/10.1257/jel.46.1.57

Bosmans, K., Decancq, K., \& Decoster, A. (2014). The relativity of decreasing inequality between countries. Economica, 81(322), 276-292. http://dx.doi.org/10.1111/ecca.12059

Bourguignon, F., \& Morrisson, C. (2002). The size distribution of income among world citizens, 1820-1990. 
American Economic Review, 92(4), 727-44. http://dx.doi.org/10.1257/00028280260344443

Firebaugh, G. (2003). Global income inequality. John Wiley \& Sons, Inc.

Goda, T., \& García, A. T. (2016). The rising tide of absolute global income inequality during 1850-2010: Is it driven by inequality within or between countries? Social Indicators Research, 130(3), 1-22. http://dx.doi.org/10.1007/s11205-015-1222-0

Haouas, I., \& Heshmati, A. (2014). Can the UAE avoid the oil curse by economic diversification? IZA $\begin{array}{llllll}\text { Discussion } & \text { Paper } & \text { Series } & \text { No. } & 8003 . & \text { Retrieved }\end{array}$ http://ftp.iza.org/dp8003.pdf\#search=\%27United+Arab+Emirates+1980s+decrease+GDP\%27

Hatase, M. (2002). Senkankinihon no kawase rate hendo to yusyutsu (Exchange fluctuation and export during the war in Japan). Kinyu Kenkyu, 21(2), 97-135. Institute for Monetary and Economic Studies, Bank of Japan. (Japanese) Retrieved from https://www.imes.boj.or.jp/research/papers/japanese/kk21-2-5.pdf

Kokubun, K., Ikemoto, Y., \& Hamashima, A. (2006). Asian economic development in the world income distribution: 1820-1996. The Memoirs of the Institute of Oriental Culture, 149, 33-56. Retrieved from http://hdl.handle.net/2261/2314

Milanovic, B. (2011). Worlds apart: Measuring international and global inequality. Princeton University Press.

Pinkovskiy, M., \& Sala-i-Martin, X. (2009). Parametric estimations of the world distribution of income.NBER Working Paper, 15433. National Bureau of Economic Research. http://dx.doi.org/10.3386/w15433

Reichlin, P. (2013). On Milanovic's idea of world inequality. Global Policy, 4(2), $211-212$. http://dx.doi.org/10.1111/1758-5899.12033

The Maddison-Project. (2013). http://www.ggdc.net/maddison/maddison-project/home.htm, 2013 version

World Bank. (2009). Part I: Reshaping economic geography. World development report (2009). Washington, DC: World Bank. Retrieved from http://siteresources.worldbank.org/INTWDRS/Resources/477365-1327525347307/8392086-132752851056 8/WDR09_bookweb_1.pdf

Yamazawa, I., \& Yamamoto, Y. (1979). Chokikeizaitokei: Suikei to bunseki (14) Boueki to kokusaisyushi (Long-term statistics: Estimate and analysis (14) Trade and international revenue and expenditure). Toyo Keizai Shinposha. (Japanese)

Zanden, J. L., Baten, J., Foldvari, P., \& Leeuwen, B. (2014). The changing shape of global inequality 1820-2000: Exploring a new dataset. Review of Income and Wealth, 60(2), 279-297. http://dx.doi.org/10.1111/roiw.12014

Appendix A. List of countries and country groups used in the analysis

\begin{tabular}{|c|c|c|c|c|c|c|}
\hline West (34) & East Europe (36) & Latin America (35) & East Asia (46) & West Asia (15) & Africa (55) & \\
\hline Austria & Albania * & Costa Rica * & China & Bahrain * & Algeria & Madagascar * \\
\hline Denmark & Former Czechoslovakia (2) & Dominican Republic * & Indonesia, including Timor until 1999 & Iraq & Benin * & Mali * \\
\hline France & Poland * & El Salvador * & Philippines & Jordan & Burkina Faso * & Mauritius * \\
\hline Germany & Romania * & Guatemala * & South Korea & Kuwait* & Burundi * & Morocco \\
\hline Italy & Former Yugoslavia (5) * & Haïti $*$ & Thailand & Lebanon & Cameroon * & Mozambique * \\
\hline Netherlands & Former USSR (15) & Honduras * & Taiwan & Oman * & Cape Verde * & Namibia $*$ \\
\hline Sweden & Brazil & Nicaragua $*$ & Burma & Saudi Arabia * & Chad* & Nigeria $*$ \\
\hline Switzerland & Chile & Panama * & Hong Kong & Syria & Comoro Islands * & Rwanda * \\
\hline United Kingdom & Colombia * & Paraguay $*$ & Malaysia & Turkey & Congo 'Brazzaville' * & São Tomé and Principe * \\
\hline Ireland & Mexico & Puerto Rico * & Nepal & United Arab Emirates * & Côte d'Ivoire * & Senegal $*$ \\
\hline Greece & Peru * & Trinidad and Tobago $*$ & Pakistan * & Yemen * & Djibouti * & Seychelles * \\
\hline Portugal & Uruguay * & Small Caribbean countries (21) & Singapore & West Bank and Gaza & Egypt & Sierra Leone $*$ \\
\hline Spain & Venezuela & & Sri Lanka & & Equatorial Guinea * & Somalia * \\
\hline \multirow[t]{4}{*}{ United States } & & & North Korea & & Guinea * & $\operatorname{Tog}_{0} *$ \\
\hline & & & Vietnam & & Guinea Bissau * & Tunisia \\
\hline & & & Small East Asian countries (24) & & Kenya * & Uganda * \\
\hline & & & & & Lesotho * & Zaire (Congo Kinshasa) * \\
\hline \multirow{2}{*}{\multicolumn{5}{|c|}{$\begin{array}{l}\text { Note. * Countries used for } 1950-2008 \text { estimates only. } \\
\text { Figures in parentheses are the number of companies. }\end{array}$}} & Liberia * & Zambia * \\
\hline & & & & & Libya & Zimbabwe * \\
\hline & & & & & & Small African countries (3) * \\
\hline
\end{tabular}


Appendix B. Estimated inequality between and within regions (129 countries)

\begin{tabular}{|c|c|c|}
\hline & Gini & Theil \\
\hline 1820 & 0.151 & 0.053 \\
\hline 1821 & 0.156 & 0.056 \\
\hline 1822 & 0.156 & 0.056 \\
\hline 1823 & 0.160 & 0.058 \\
\hline 1824 & 163 & .061 \\
\hline 1825 & 0.163 & .061 \\
\hline 1826 & 0.166 & 0.063 \\
\hline 1827 & 0.168 & 0.064 \\
\hline 1828 & 0.170 & 066 \\
\hline 1829 & 173 & .068 \\
\hline 1830 & 0.175 & 0.069 \\
\hline 1831 & 0.178 & 0.071 \\
\hline 1832 & 0.182 & 0.074 \\
\hline 1833 & 0.183 & 0.074 \\
\hline 1834 & 0.186 & 0.076 \\
\hline 1835 & 0.190 & 0.080 \\
\hline 1836 & 0.192 & 0.082 \\
\hline 1837 & 0.193 & 0.082 \\
\hline 1838 & 0.199 & 0.087 \\
\hline 1839 & 0.200 & 0.089 \\
\hline 1840 & 0.202 & 089 \\
\hline 1841 & 0.203 & .089 \\
\hline 1842 & 0.201 & 0.087 \\
\hline 1843 & 0.205 & 0.089 \\
\hline 1844 & 0.211 & 0.094 \\
\hline 1845 & 0.213 & .096 \\
\hline 1846 & .217 & 101 \\
\hline 1847 & 0.224 & 0.107 \\
\hline 1848 & 0.224 & 0.107 \\
\hline 1849 & 0.228 & 0.111 \\
\hline 1850 & 0.230 & 112 \\
\hline 1851 & 0.235 & 117 \\
\hline 1852 & 0.242 & 123 \\
\hline 1853 & 0.243 & 0.125 \\
\hline 1854 & 0.250 & .131 \\
\hline 1855 & 0.251 & 132 \\
\hline 1856 & 0.262 & 143 \\
\hline 1857 & 0.268 & 149 \\
\hline 1858 & 0.274 & .154 \\
\hline 1859 & 0.275 & 0.155 \\
\hline 1860 & 0.283 & 163 \\
\hline 1861 & 0.283 & .163 \\
\hline 1862 & 0.290 & 0.170 \\
\hline 1863 & 0.296 & 0.176 \\
\hline 1864 & 0.301 & 181 \\
\hline 1865 & 0.303 & 0.184 \\
\hline 1866 & 0.307 & .188 \\
\hline 1867 & 0.305 & .185 \\
\hline 1868 & 0.314 & 0.196 \\
\hline 1869 & 0.317 & 0.200 \\
\hline 1870 & 0.321 & 206 \\
\hline 1871 & 0.326 & .212 \\
\hline 1872 & 0.333 & 0.220 \\
\hline 1873 & 0.336 & .223 \\
\hline 1874 & 0.340 & 228 \\
\hline 1875 & 0.345 & 0.233 \\
\hline 1876 & 0.341 & 227 \\
\hline 1877 & 0.343 & 29 \\
\hline 1878 & 0.346 & 0.231 \\
\hline 1879 & 0.348 & 233 \\
\hline 1880 & 0.363 & 251 \\
\hline 1881 & 0.368 & 0.257 \\
\hline 1882 & 0.376 & 66 \\
\hline 1883 & 0.380 & 70 \\
\hline 1884 & 0.372 & 261 \\
\hline 1885 & 0.368 & 255 \\
\hline 1886 & 0.37 & 60 \\
\hline 1887 & 0 & 63 \\
\hline 1888 & 0. & 44 \\
\hline 1889 & 0 & 78 \\
\hline 1890 & 0 & \\
\hline 1891 & 0.393 & 285 \\
\hline 1892 & 0 & \\
\hline 1893 & 0. & 3 \\
\hline 1894 & 0.386 & 71 \\
\hline 1895 & 0 & \\
\hline 1896 & 0 & 6 \\
\hline 1897 & 0.399 & 89 \\
\hline & & \\
\hline 1899 & 0.418 & 18 \\
\hline 1900 & 0.418 & \\
\hline 1901 & 0 & \\
\hline 1902 & 0.418 & 6 \\
\hline 19 & & \\
\hline 1904 & 0 & 4 \\
\hline 1905 & 0.42 & 27 \\
\hline 1906 & & \\
\hline 1907 & 0.44 & \\
\hline O & & \\
\hline 1909 & 0.435 & 32 \\
\hline 1910 & 0.434 & 31 \\
\hline & & \\
\hline 12 & 445 & 347 \\
\hline 191 & 0.450 & \\
\hline 1914 & 0.436 & 0.331 \\
\hline
\end{tabular}


Appendix B. Estimated inequality between and within regions (129 countries, continued)

\begin{tabular}{|c|c|c|c|}
\hline & Gini & Theil & \\
\hline 1915 & 0.442 & 0.340 & $(100.0)$ \\
\hline 1916 & 0.455 & 0.363 & $(100.0)$ \\
\hline 1917 & 0.450 & 0.354 & $(100.0)$ \\
\hline 1918 & 0.463 & 0.380 & $(100.0)$ \\
\hline 1919 & 0.450 & 0.356 & $(100.0)$ \\
\hline 1920 & 0.454 & 0.359 & $(100.0)$ \\
\hline 1921 & 0.444 & 0.341 & $(100.0)$ \\
\hline 1922 & 0.453 & 0.355 & $(100.0)$ \\
\hline 1923 & 0.467 & 0.382 & $(100.0)$ \\
\hline 1924 & 0.470 & 0.387 & $(100.0)$ \\
\hline 1925 & 0.474 & 0.392 & $(100.0)$ \\
\hline 1926 & 0.477 & 0.398 & $(100.0)$ \\
\hline 1927 & 0.480 & 0.403 & $(100.0)$ \\
\hline 1928 & 0.481 & 0.405 & $(100.0)$ \\
\hline 1929 & 0.485 & 0.412 & $(100.0)$ \\
\hline 1930 & 0.470 & 0.385 & $(100.0)$ \\
\hline 1931 & 0.456 & 0.359 & $(100.0)$ \\
\hline 1932 & 0.435 & 0.326 & $(100.0)$ \\
\hline 1933 & 0.437 & 0.326 & $(100.0)$ \\
\hline 1934 & 0.456 & 0.352 & $(100.0)$ \\
\hline 1935 & 0.458 & 0.357 & $(100.0)$ \\
\hline 1936 & 0.465 & 0.372 & $(100.0)$ \\
\hline 1937 & 0.475 & 0.387 & $(100.0)$ \\
\hline 1938 & 0.476 & 0.386 & $(100.0)$ \\
\hline 1939 & 0.487 & 0.404 & $(100.0)$ \\
\hline 1940 & 0.494 & 0.418 & $(100.0)$ \\
\hline 1941 & 0.519 & 0.473 & $(100.0)$ \\
\hline 1942 & 0.543 & 0.529 & $(100.0)$ \\
\hline 1943 & 0.565 & 0.587 & $(100.0)$ \\
\hline 1944 & 0.577 & 0.624 & $(100.0)$ \\
\hline 1945 & 0.574 & 0.633 & $(100.0)$ \\
\hline 1946 & 0.544 & 0.549 & $(100.0)$ \\
\hline 1947 & 0.542 & 0.528 & $(100.0)$ \\
\hline 1948 & 0.545 & 0.527 & $(100.0)$ \\
\hline 1949 & 0.546 & 0.522 & $(100.0)$ \\
\hline 1950 & 0.555 & 0.536 & $(100.0)$ \\
\hline 1951 & 0.555 & 0.539 & $(100.0)$ \\
\hline 1952 & 0.549 & 0.527 & $(100.0)$ \\
\hline 1953 & 0.548 & 0.525 & $(100.0)$ \\
\hline 1954 & 0.545 & 0.516 & $(100.0)$ \\
\hline 1955 & 0.549 & 0.524 & $(100.0)$ \\
\hline 1956 & 0.543 & 0.513 & $(100.0)$ \\
\hline 1957 & 0.542 & 0.511 & $(100.0)$ \\
\hline 1958 & 0.531 & 0.490 & $(100.0)$ \\
\hline 1959 & 0.538 & 0.505 & $(100.0)$ \\
\hline 1960 & 0.540 & 0.506 & $(100.0)$ \\
\hline 1961 & 0.551 & 0.522 & $(100.0)$ \\
\hline 1962 & 0.556 & 0.533 & $(100.0)$ \\
\hline 1963 & 0.555 & 0.533 & $(100.0)$ \\
\hline 1964 & 0.552 & 0.529 & $(100.0)$ \\
\hline 1965 & 0.555 & 0.538 & $(100.0)$ \\
\hline 1966 & 0.557 & 0.544 & $(100.0)$ \\
\hline 1967 & 0.562 & 0.552 & $(100.0)$ \\
\hline 1968 & 0.569 & 0.566 & $(100.0)$ \\
\hline 1969 & 0.567 & 0.562 & $(100.0)$ \\
\hline 1970 & 0.560 & 0.549 & $(100.0)$ \\
\hline 1971 & 0.561 & 0.552 & $(100.0)$ \\
\hline 1972 & 0.565 & 0.562 & $(100.0)$ \\
\hline 1973 & 0.565 & 0.563 & $(100.0)$ \\
\hline 1974 & 0.564 & 0.560 & $(100.0)$ \\
\hline 1975 & 0.559 & 0.547 & $(100.0)$ \\
\hline 1976 & 0.563 & 0.556 & $(100.0)$ \\
\hline 1977 & 0.561 & 0.553 & $(100.0)$ \\
\hline 1978 & 0.559 & 0.549 & $(100.0)$ \\
\hline 1979 & 0.564 & 0.556 & $(100.0)$ \\
\hline 1980 & 0.557 & 0.548 & $(100.0)$ \\
\hline 1981 & 0.558 & 0.543 & $(100.0)$ \\
\hline 1982 & 0.549 & 0.529 & $(100.0)$ \\
\hline 1983 & 0.549 & 0.526 & $(100.0)$ \\
\hline 1984 & 0.546 & 0.525 & $(100.0)$ \\
\hline 1985 & 0.547 & 0.523 & $(100.0)$ \\
\hline 1986 & 0.546 & 0.522 & $(100.0)$ \\
\hline 1987 & 0.544 & 0.517 & $(100.0)$ \\
\hline 1988 & 0.542 & 0.517 & $(100.0)$ \\
\hline 1989 & 0.544 & 0.521 & $(100.0)$ \\
\hline 1990 & 0.542 & 0.518 & $(100.0)$ \\
\hline 1991 & 0.539 & 0.514 & $(100.0)$ \\
\hline 1992 & 0.534 & 0.507 & $(100.0)$ \\
\hline 1993 & 0.527 & 0.495 & $(100.0)$ \\
\hline 1994 & 0.523 & 0.491 & $(100.0)$ \\
\hline 1995 & 0.512 & 0.473 & $(100.0)$ \\
\hline 1996 & 0.511 & 0.472 & $(100.0)$ \\
\hline 1997 & 0.511 & 0.471 & $(100.0)$ \\
\hline 1998 & 0.513 & 0.480 & $(100.0)$ \\
\hline 1999 & 0.510 & 0.477 & $(100.0)$ \\
\hline 2000 & 0.506 & 0.468 & $(100.0)$ \\
\hline 2001 & 0.496 & 0.449 & $(100.0)$ \\
\hline 2002 & 0.487 & 0.430 & $(100.0)$ \\
\hline 2003 & 0.474 & 0.407 & $(100.0)$ \\
\hline 2004 & 0.465 & 0.389 & $(100.0)$ \\
\hline 2005 & 0.457 & 0.375 & $(100.0)$ \\
\hline 2006 & 0.447 & 0.358 & $(100.0)$ \\
\hline 2007 & 0.440 & 346 & $(100.0)$ \\
\hline 2008 & 0.429 & 0.327 & $(100.0)$ \\
\hline
\end{tabular}




\section{Appendix C. Estimated inequality between and within regions ( 222 countries)}

\begin{tabular}{|c|c|c|c|c|c|c|c|c|c|c|c|c|c|c|c|c|c|c|c|}
\hline \multirow[b]{2}{*}{1950} & \multirow{2}{*}{$\begin{array}{l}\text { Gini } \\
0.548\end{array}$} & \multicolumn{2}{|c|}{ Theil } & \multicolumn{2}{|c|}{ Between Region } & \multicolumn{2}{|c|}{ Within Region } & \multicolumn{2}{|c|}{ Within West } & \multicolumn{2}{|c|}{ Within East Europe } & \multicolumn{2}{|c|}{ Within Latin America } & \multicolumn{2}{|c|}{ Within East Asia } & Within We & t Asia & Within A & rica \\
\hline & & 0.528 & $(100.0)$ & 0.434 & $(82.2)$ & 0.094 & $\begin{array}{l}(17.8) \\
\end{array}$ & 0.054 & $\begin{array}{l}(10.2) \\
\end{array}$ & 0.003 & $\begin{array}{l}(0.6) \\
\end{array}$ & 0.009 & 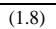 & 0.019 & $\begin{array}{l}(3.7) \\
\end{array}$ & 0.003 & $(0.5)$ & 0.006 & (1.0) \\
\hline 1951 & 0.548 & 532 & $(100.0)$ & 0.438 & $(82.4)$ & 0.093 & (17.6) & 0.053 & (9.9) & 0.003 & $(0.5)$ & 0.009 & (1.8) & 0.020 & (3.9) & 0.003 & $(0.5)$ & 0.005 & .0) \\
\hline 1952 & & & $(100.0)$ & 0.431 & & & & & & & & & 7) & & $(4.2)$ & & 5) & & \\
\hline 1953 & 443 & 21 & $(100.0)$ & 431 & $(82.7)$ & .090 & $(17.3)$ & 47 & (9.1) & 003 & (0.5) & .009 & (1.7) & .023 & (4.5) & 003 & (0.6) & .005 & $1.0)$ \\
\hline 1954 & & 12 & $(100.0)$ & & & & & & (7.9) & & & 09 & $.8)$ & & $(4.8)$ & 03 & $(0.7)$ & .005 & .0) \\
\hline 1955 & 0.545 & 22 & $(100.0)$ & 0.436 & (83.4) & 0.087 & (16.6) & 0.040 & (7.6) & & $(0.5)$ & 0.009 & (1.8) & 0.026 & (5.0) & .003 & $(0.6)$ & 0.005 & .0) \\
\hline 1956 & 541 & 13 & $(100.0)$ & 429 & $3.6)$ & 0.084 & & & (7.0) & & (0. & & (19) & & (5.2) & & $(0.6)$ & .005 & 0 \\
\hline 1957 & 0.541 & 12 & $(100.0)$ & 0.428 & $(83.7)$ & 0.083 & (16.3) & 32 & (6.3) & .003 & $(0.6)$ & 0.011 & (2.1) & .029 & (5.7) & .003 & $(0.6)$ & .005 & 1.0) \\
\hline 1958 & 0.531 & 93 & $(100.0)$ & 0.414 & $(84.0)$ & 0.079 & & 28 & (5.7) & & $(0.6)$ & 0.010 & (2.1) & .029 & (5.9) & .003 & $(0.6)$ & .005 & (1.1) \\
\hline 1959 & 358 & 07 & $(100.0)$ & 0.424 & (83.7) & 0.083 & & 30 & (5.9) & & $(0.5)$ & 0.009 & (1.8) & 032 & (6.4) & 03 & $(0.6)$ & .006 & 1.1) \\
\hline 1960 & & 09 & $(100.0)$ & 423 & 32 & 0.086 & & & (5.4) & & & 09 & & & (7.5) & & $(0.6)$ & .006 & .1) \\
\hline 1961 & & & $(100.0)$ & & & & & & (4.6) & & & & & & (9.1) & & & 06 & (1.1) \\
\hline 1962 & & 34 & $(100.0)$ & 0.439 & & 0.095 & & 23 & (4.4) & & & 0.008 & $.5)$ & 052 & (9.8) & 03 & $(0.7)$ & .005 & (1.0) \\
\hline 1963 & & & $(100.0)$ & & & 96 & & & (4.1 & & & & (1.4) & & $(10.3)$ & & 6) & .006 & .1) \\
\hline 1964 & & & $(100.0)$ & 434 & & 0.099 & (18 & & (3.9 & & (0. & 0.008 & (1.5) & & (10.9) & & $(0.6)$ & .006 & 1.1) \\
\hline 1965 & 0. & 41 & $(100.0)$ & 0.440 & $(81.2)$ & 0.102 & & & $(4.0)$ & & & & (1.7) & & $(11.0)$ & & $(0.6)$ & .006 & 1.1) \\
\hline 1966 & & 49 & $(100.0)$ & 42 & & 0.107 & & & (4. & & & & & & 11.8) & & 7) & .006 & 1.1) \\
\hline 1967 & & & $(100.0)$ & 443 & & 0.115 & & & (3.7) & & & & & & 3) & & 7) & 07 & .2) \\
\hline 1968 & & & (100 & & & 0.126 & & & (3. & & & & & & & & & & 3) \\
\hline 1969 & & 69 & $(100.0)$ & 36 & (7) & 0.132 & 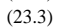 & & $(3.1)$ & & & & & & (16.5) & & $(0.7)$ & 07 & (1.3) \\
\hline 1970 & & & $(100.0)$ & & & & & & & & & & & & & & & 07 & 1.3) \\
\hline 19 & & & $(100.0)$ & & & & & & & & & & & & & & & 07 & \\
\hline 1972 & & 71 & $(100.0)$ & 5 & 0 & 45 & (2) & & 0 & & & & ) & 11 & 951 & & & & .2) \\
\hline 1973 & & & $(100.0)$ & & & & & & & & & & & & 0) & & $0)$ & 07 & (1.1) \\
\hline 1974 & & & $(100.0)$ & & & & (24 & & & & & & & & & & & 07 & (1.2) \\
\hline 19 & & & & & & & & & & & & & & 11 & & & & 07 & 2) \\
\hline 1976 & & 67 & $(100.0)$ & 423 & (7 7 & 0.143 & (2 & & (1.9) & & & & (11) & 114 & $(20.0)$ & & & .007 & (1.3) \\
\hline 1977 & & & $(100.0)$ & & & & & & & & & & & & & & & & (1.2) \\
\hline 1978 & & & (100.0) & & & & & & & & & & & & $(2)$ & & & & (1.3) \\
\hline 19 & & & & & & & & & & & & & & & & & & & 3) \\
\hline 1080 & & & $(100.0)$ & & & & & & & & & & & & & & & & (1.4) \\
\hline 19 & & & $(100.0)$ & & & & & & & & & & & & ) & & )) & & 1.4) \\
\hline 1982 & & & $(100.0)$ & & & & & & & & & & & & (22.6) & 05 & $(0.9)$ & 08 & (1.5) \\
\hline 1983 & & & & & & & & & (1. & & & & & & & & $(0.7)$ & & (1.5) \\
\hline & & & (10 & & & & & & & & & & & & & & & & (1.5) \\
\hline 19 & & & (100 & & & & & & & & & & & & t & & & & 5) \\
\hline 1986 & & & & & & & & & & & & & & & (22.3) & & & & (1.4) \\
\hline 1987 & & & & & & & & & & & & & & & & & 5) & & (1.4) \\
\hline & & & & & & & & & & & & & & & & & & & .4) \\
\hline & & & (1 & & & & & & & & & & & & & & & & 3) \\
\hline 1990 & & & (100 & & & & & & & & & & & & 2) & & 6) & & (1.3) \\
\hline 1991 & & & (100. & & & & & & & & & & & & 06 & & & & (1.3) \\
\hline & & & & & & & & & & & & & & & & & & & ( \\
\hline 1993 & & & $(100$ & & & & & & & & & & & & $(2$, & 05 & ) & 07 & .4) \\
\hline 1994 & & 44 & (100 & & & & & & & & & & & & 6) & 05 & 8) & 08 & (1.4) \\
\hline 1995 & & & & & & & & & & & & & & & & & & & (1.4) \\
\hline 1996 & & & & & & & & & & & & & & & & & & & \\
\hline 199 & & & & & & & & & & & & & & & & & & & (1.5) \\
\hline 19 & & & (100 & & & & & & & & & & & & & & 8) & & (1.5) \\
\hline & & & & & & & & & & & & & & & & & & & \\
\hline 2000 & & & & & & & & & & & & & & & ( & 04 & & 08 & 6 \\
\hline 2001 & & & $(100.0)$ & & & & & & & & & & & 19 & (22.9) & 04 & .7) & 09 & (1.7) \\
\hline 2002 & & & (100. & & t & & 28 & & (1. & & $(0$ & & (1. & & (23.2) & 0.004 & $(0.7)$ & 09 & (1.7) \\
\hline OU. & & & & & & & & & & & & & & & & & & & \\
\hline 200 & & & & & & & & & & & & & & & , & & & & \\
\hline 2005 & & & $(100.0)$ & & (t) & & & & & & & & (1 & & $(24.0)$ & 05 & $(1.0)$ & 09 & $(2.0)$ \\
\hline 200 & & & $(100.0)$ & & & & & & & & & & & & (24) & & & 09 & (2.0) \\
\hline & & & & & & & & & & & & & & & & & (1. & 09 & \\
\hline 2008 & 0.484 & 0.413 & $(100.0)$ & 0.283 & (68.6) & 0.130 & (31.4) & 0.007 & (1.7) & 0.001 & $(0.3)$ & 0.006 & (1.4) & 0.102 & (24.6) & 0.005 & (1.2) & 0.009 & (2.3) \\
\hline
\end{tabular}

\section{Copyrights}

Copyright for this article is retained by the author(s), with first publication rights granted to the journal.

This is an open-access article distributed under the terms and conditions of the Creative Commons Attribution license (http://creativecommons.org/licenses/by/4.0/). 